\title{
The Importance of Cooperative Work in the Faculty and in the Classroom
}

\author{
M. G. Montoya, R. Herrada, C. Gil, \\ F. G. Montoya and A. Alías \\ University of Almeria \\ Spain
}

\section{Introduction}

The present work highlights the interest in improving teaching in the University by understanding the changes which arise when lecturers work cooperatively and extend this educational practice to their classrooms. However, it would seem equally appropriate to refer to the teaching team as a collective agent in the students' education and also as a model. On the other hand, we should bear in mind the whole educational centre (Faculty and University) both as the field educational development and as the field of more informal learning.

In a society which seems to be dominated by individualism and competitiveness, why is it that in the educational field more value has been given recently to cooperative work? The answer surely lies in the economic factor and our obsession with efficiency, in particular the widespread belief that tomorrow's society will demand and place a high value on work teams based on cooperation. Duran Gisbert considers that the capacity to cooperate is one of the main interpersonal competences of a "knowledge workers", (Gisbert, 2001). In the new economic framework, work is organized in interdisciplinary and multicultural teams which are capable of working in contexts which are subject to rapid change. In such teams participation and a cooperative style of work are highly valued.

Given this scenario for the future, it will be necessary for both students and lecturers to develop cooperation in the classroom in order to be prepared for the society of tomorrow. When lecturers cooperate in their teaching work they are supporting and promoting a climate of cooperation in their classrooms, their universities and in society as a whole.

Society needs its future citizens to learn cooperatively as opposed to the individualism in which social and work relationships are so steeped. We should combat the desire to convert learning into a competitive scenario which sets goals reserved for a few "excellent" students. Individualism in the classroom gives rise to anachronic situations such as the students considering it an obstacle "to have to wait for the group to develop a piece of work in which all those involved learn and reach a common goal".

Interaction among teaching staff is not promoted either, since lecturers are mainly required to master the subject they teach. The more they specialize, the further they go from shared knowledge with other areas, and in particular from the common core of the students 
learning process which is shared by all those involved in the teaching task. Moreover, specialization usually leads us to consider content as the main concern, "teaching everything or what is relevant", as opposed to encouraging students to acquire the tools which will give them access to knowledge.

The idea is still held that working separately the students will be able to put the pieces of the puzzle together and give them some coherence. In so doing the students will become citizens who are capable of facing up to life. It would be a mistake to believe that everyone has the same chance of solving the puzzle, or that they will do so at more or less the same time. Likewise, we would be mistaken to think that if the pieces of the puzzle are designed separately they will fit together exactly.

On the other hand, the creation of the European Higher Education Space has resulted in the definition of a new educational paradigm in university studies, as has been made clear in the different international and national forums related to this context (EHES, 2005), (Tunning, 2002). The typical features of this new educational model require the development of a professional profile in which the roles and activities of students and lecturers are no longer the traditional ones. Modifications must therefore be made to both the content of the subjects and especially the way in which they are taught, affecting lecturers and students equally.

The principal features of the intended educational model which make it a more effective tool for the challenges which have to be confronted are (Fernández, 2006):

- A learning-centred educational model, requiring a shift from teaching to learning, and particularly teaching to learn to learn, and to learn for life.

- An educational model centred on autonomous learning of the student under tutorship of the lecturers.

- An educational model focussing on the results of learning, expressed in terms of generic and specific competences.

- An educational model that focusses on the learning process - education as cooperative work between lecturers and students.

- An educational model that demands a new definition of the learning-teaching activities.

- $\quad$ An educational model which proposes a new organization of learning: modularity, multidisciplinary and cross-disciplinary curricular spaces, as part of the global educational project (Curriculum).

- $\quad$ An educational model that makes strategic use of evaluation, making it an integral part of the learning-teaching activities. There should be a revaluation of the formative or continuous evaluation and a review of the final or qualificative evaluation.

- $\quad$ An educational model that measures the work of the student, using the ECTS as a tool to construct the curriculum, taking the competences or results of learning as a basis. This model will also act as tool to guarantee the transparency of the different systems of higher education.

- An educational model which places greater importance on technologies of the information and the communication and their possibilities to develop new ways of learning. In this sense, one of the basic recommendations for the Implantation of the European Higher Education Space is that the work of educational innovation should be carried out by a coordinated educational team and not in an individual way in each of the subjects. 
Nevertheless, it is well known that the most university lecturers work individually, which has led students to regard subjects as isolated entities without any links between them. It goes without saying that the students' workload at any given time is not known.

Given this situation and bearing in mind the new educational paradigm, one of the challenges is to get lectures from the same degree and the same year to work together in teaching teams, responsible for organizing and scheduling all those activities which affect the same group of students.

Moreover, lecturers who cooperate with their colleagues in a team also tend to practise this activity in their classes, as cooperative work is not a technical process, but rather an attitude which impregnates all aspects of the educational centre's life and shapes the culture of cooperation, which extends to all times and situations.

On the other hand, in the specialist literature, (Aronson \& Patnoe, 1997; Johnson et al., 1991; Johnson et al., 2006), there is sufficient support for cooperative learning as a strategy which improves both the quantity and the quality of the work of a group of students.

The present chapter, based on the experiences of our teaching group, named COMPING, (Montoya et al., 2007; Montoya et al., 2008), aims to show that coordinated action can achieve both educational and social aims which would otherwise not be attained. It also shows that as a result of collective action we obtain benefits which are both sought after and shared by all: holistic education of the student and the professional development of the lecturer.

Although most of the studies carried out on teamwork among teachers have focussed on Primary and Secondary Education (López, 2007), the majority of their considerations can also be applied to the university. In our specific case, the fact of belonging to a teaching group has allowed us to work in conjunction as a team, enhancing our teaching skills with a constant process of reflection, training and innovation, through a meeting point and a strategy of permanent communication using taking advantage of a virtual learning platform.

The rest of this work, will attempt to answer some of the following questions: Do lecturers work as a team?, Do lecturers need to develop the competence of teamwork of cooperative work in teaching teams?, What problems arise from teamwork?, What is the basis for cooperative work?, Why is teamwork important?, Which competences does it develop?.

\section{Do Lecturers work as a team? Do we need to develop this competence? Why is individualism the prevalent attitude among lecturers?}

Despite consensus on the need to work as a team and to collaborate, lecturers very seldom do so. Individual work, and all too often individualism, are present in the daily work of numerous lecturers who work independently of their colleagues and who do not encourage cooperative work in their classes.

One of the major difficulties facing cooperative work, as has been explained earlier, is the competitiveness and individualism which characterizes our teaching faculties and our society as a whole. Many writers on this topic agree that individualism, secretism and isolation are constantly to be found in our educational system: most lecturers continue to teach alone, in the isolated atmosphere of their classrooms. 
One of the fundamental causes of individualism on the part of lecturers is the conditions in which they work, and more generally, the regulations which impose on them the structure of their post. The fact that the initial training of lecturers, and the whole of their university education, tends to give teamwork a minor or secondary role, reinforces in future lecturers the idea prevalent in our society that this way of working is only useful for tasks of little importance, as relevant activities tend to be based on competitiveness and efficiency.

Competitive societies establish a more or less open struggle between the people or groups they comprise. In such a context the interdependence of aims or resources is impossible, since there are relationships of negative reciprocity in which the projects of others are felt to interfere with one's own. Competitiveness complicates and can even prevent interaction between lecturers (Gitlin, 1987).

Competition creates a social environment which is contrary to cooperation, but on occasions lecturers do not work together on teaching tasks due to a lack of stimuli, since, on the whole, teaching work is not valued as highly as research tasks.

Another disadvantage which arises from cooperation is the so-called balkanization (Day, 1999). This refers to a type of cooperation which divides and separates lecturers into isolated, and often confronted, sub-groups within the same department or faculty. Balkanization can be said to occur when lecturers work together more closely than in an individualistic society, but in groups, remaining loyal and linking themselves to a given collective of colleagues. A radical proposal would be to suppress departmental organizations in favor of course/degree-level ones (teaching teams on both a horizontal and a vertical plane). This would approach the mobile mosaic in which universities would have more permeable departmental limits, lecturers could belong to more than one department, their category would not be so important, and this type of organization and its leadership would be expected to change in time. Once differences in prestige and power within the departments are eliminated or at least reduced, leadership and its rewards would also be reduced, and the third step would be to debate conflicts and solve them in a continual process of sincere, democratic and ethical procedures. In this way, power struggles would not lead to new hierarchies or balkanization processes.

As a rule, lecturers find it difficult to work as a team even when they want to. They have no tradition of working in this way, and neither have they been prepared to do so. Book states that even though teachers might like to work cooperatively and share their ideas with their colleagues, they do not know how to do so, (Book, 1996).

Educational institutions demand that they collaborate with their colleagues in certain unalterable conditions. Cooperation can be encouraged, but it cannot be required of lecturer, as that would contradict the very principles on which it is based.

\section{Why is cooperative work important? On what is it based?}

Most lecturers agree on the need for cooperation in their teaching work in order to innovate, to change and in general to develop the educational system. Cooperating and collaborating is not easy in our social and cultural context, but our experience as a teaching group has allowed us to confirm that teams of lecturers working in conjunction support one another in order to reach shared goals. It is true that this activity goes against the grain of the neoliberal globalised view which tries to create a single pedagogic belief based on values such as individualism, competitiveness, obsession with efficiency and separating the means from 
the end. However, it is also true that the work of these groups of lecturers is creating an alternative horizon. Guided by a utopian aim which implies the practice of solidarity and social justice, they also contribute towards a truly democratic society. In short, by cooperating we are part of the necessary cultural battle to combat neoliberalism and create a culture of cooperation.

From the perspective that these thoughts provide we can understand the reasons why collaborating is not an easy task, but also why it is indispensable one.

\subsection{Requirements for cooperative work}

Cooperative work does not merely imply that several people work together. Those people must be working towards common goals in such a way that individual team members are not able to achieve their aims unless their fellow team members achieve theirs. In cooperative work nobody succeeds at the expense of others, and individual triumph is incompatible with collective failure. A set of objectives which unite the team, the common goal, is of paramount importance in teamwork. These shared goals must motivate team members to carry out a common task. According to (Johnson et al., 1991) cooperation consists of "working together to achieve common goals". These authors also outline the conditions which cooperative teamwork should fulfill:

1. There should exist positive interdependence of aims, resources and roles, so that individual success and group success are interrelated. In a cooperative scenario individuals strive to obtain results which are beneficial both for themselves and for the rest of the group.

2. There should exist both individual and group responsibility regarding the attainment of aims.

3. The group as a whole must accept responsibility for achieving the proposed aims, while at the same time individual members are responsible for successfully carrying out their corresponding part of the task. Nobody can oppose the work of other group members and responsibilities cannot be diluted within the group.

4. Group members should possess the skills of interpersonal and group exchange.

5. There should be an awareness of collective functioning which allows the group as a whole to asses to what extent the aims are being achieved and efficient working relationships are being maintained. The group must decide whether their members' actions have positive or negative repercussions, and consequently they should either encourage or modify said actions.

6. There should exist face to face interaction, in such a way that proximity and dialogue allow the creation of dynamics of help, support and reinforcement among team members. In this way they acquire a personal commitment to one another and to their common goals.

The interdependent structure of aims intrinsic to cooperative work contrasts sharply with the independent objectives of individual work and the opposing goals which are characteristic of competitive tasks. In individual work each participant works in isolation, and in competitive tasks each individual competes with the others, and the achievement of one individual's aims is detrimental to those of the others. In the opinion of Little in (Little, 1996), the above-described interdependence of aims also constitutes the defining 
characteristic of cooperation and it is manifested in the fact that each member of the group promotes the growth of the others.

Sharing educational aims constitutes, especially for Rosenholtz, one of the conditions which influence the depth with which lecturers collaborate and offer one another advice and support. For this author, whether or not there is concensus regarding educational aims is most important. She considers that when there is a moderate or low degree of concensus regarding aims, lecturers tend to stress their students' mistakes rather than their achievements. However, when there is a high degree of concensus and shared aims, desires and values, the teaching staff give priority to educational principles and the students' interests, thus creating a wave of opinion which affects even new arrivals and leads to a positive line of work, ( Rosenholtz, 1989).

Not only does cooperative work offer a way to improve the completion of tasks, it also constitutes a different approach to teaching, providing a novel response to habitual teaching problems.

Cooperative activities must not be promoted by external compensation or maintained as compulsory tasks. As such, the basic requirement for carrying out cooperative activities is the existence of shared objectives. Going back to the idea that the existence of common goals is the basic characteristic which allows us to define teamwork, we could say that sharing teaching goals constitutes a fundamental and nonnegotiable requirement on which teamwork among teachers must be based.

Democracy and equality of opportunities are essential elements for producing the communication which forms the basis of cooperative work. Arnaus develops this idea when explaining that only horizontal exchange favors dialogue, since self-sufficiency and the feeling that one is in a superior hierarchical position have quite the opposite effect, (Arnaus, 1999).

One of the most interesting and valuable cooperative strategies is investigation-action, which considers that education is made up of structures whose change cannot be brought about by any one individual, but rather by a process of combined reflection in which the participants develop their own solutions to the problems they face. The cooperative nature of investigation-action is stressed, claiming that this activity is the missing link towards collaboration among teachers in which cooperative work acquires a central role.

a) We can identify the teaching teams that have carried out cooperative work by the activities the lecturers employ.

b) When the lecturers get involved frequently and progressively in dialogues regarding teaching.

c) When they observe one another frequently and provide constructive criticism on each other's teaching.

d) When they propose, design, research, evaluate and prepare teaching materials as a group.

e) When they learn from others while teaching. 


\subsection{Conditioners for the practice of cooperation}

Cooperation is considered to be impossible if there are not equal conditions to express one's opinion, decide and act. Several authors stress that hierarchy puts a brake on the possibility of dialogue and prevents collaboration; besides citing (Freire, 1984), we could also refer to (Habermas, 1997), for whom any collaborative work must be carried out in an ideal situation in which all those affected should have equal right of speech. Hierarchy is contradictory to equal opportunities and therefore makes it impossible for true collaboration to take place.

However, our own experience leads us to agree completely with (Hargreaves, 1995) in that the practice of true cooperation reduces the workload, as responsibilities and pressure are shared.

In short we can say that in the course of our work we have seen that true collaboration cannot be imposed, as making it compulsory produces maladjusted cooperative practices, namely artificial collegiality and balkanization. The results of our experience allow us to state, to use a botanical simile, that collaboration is like a wild plant which will grow wherever it finds a favourable habitat, but which is ill-adapted to life in captivity. It cannot be cultivated in a nursery, but if we wish to maintain and promote it in its natural environment, we must provide it with suitable conditions in which to evolve.

We have already remarked that the prevalent values in our society prevent cooperation from flourishing. The individualism and competitiveness promoted by neoliberalism imply a division of labour based on considerations of efficiency. This means that cooperation is often relegated to minor roles or adopts maladjusted forms which limit it to the allocation of tasks, not really intending that it should work towards a common goal. Nevertheless, though cooperation is not always considered a value, it is necessary to create a culture of collaboration in which it practised and promoted. This is the opinion of (Fullan, 2001), who states that without the capabilities of collaboration and relating it is not possible to learn enough to become an agent of social improvement:

"Our ability to learn is limited if we remain isolated. The ability to collaborate, on a small or large scale, is becoming one of the basic requirements of postmodern society. Personal strength, providing it is open (i.e. directed toward research), and efficient collaboration go hand in hand - indeed, without personal strength collaboration would have more form than content. Personal skills and group skills feed off one another in learning organisations. People need one another to learn and carry out projects", (Fullan, 2001).

\section{Why have we decided to work as a team? What are the benefits for students, lecturers and the faculty as a whole?}

On the whole it is fair to say that education is considered a difficult task and a challenge to teachers. Even the most experienced teachers require assistance, and if they ask for help their professional value is by no means questioned. In a cooperative working environment help is given and offered in order to attain common goals, and this undermines the selfesteem of nobody, rather it is considered necessary and recommendable (Rosenholtz, 1989). Cooperative thinking regards education as a collective task and offers the necessary conditions to improve it via analysis, experimentation and peer-evaluation. Along these lines, Clemente Linuesa explains some of the advantages of cooperative work: "The collaborative culture leads to processes of enrichment which are fomented by dialogue, debate and even confrontation and arguments. This may well be a source of difficulties, but 
these will undoubtedly be offset by the benefits obtained. Moreover, these processes allow all uncertainties and doubts about the educational process to be shared. Sharing common problems is a way of learning to solve them, whereas the fear of failure often arises from the feeling of isolation. Cooperation foments an atmosphere of trust, of being open to the experiences of others, and this provides the teacher with greater confidence", (Clemente Linuesa, 1999).

Another aspect to bear in mind is the desprofessionalization in the integral education of specific people which arises from the division of education into multiple disciplines, each of which has a group of specialised teachers. According to (Martínez Bonafé, 1998), this division of work separates the concept of education from putting it into practice, and the teacher becomes a technician carrying out what is prescribed. This in turn demands a concerted effort of cooperation within the teaching team (Gimeno Sacristán, 1988). Cooperative work, then, makes very clear sense in our society, in our educational system in general and in the University in particular, and there is obviously a need for it, even though it does not correspond to predominant values. This need demands that we work towards a culture in which cooperation is not only possible, but becomes habitual practice. "Dewey states that education is carried out in social interaction by means of communication. Cooperation is one the principles which must guide teachers to develop their teaching activity with students and to work with their colleagues/peers. Rather than facilitating education, processes of cooperation actually constitute the very essence of education" (Angulo Rasco, 2000).

\subsection{Benefits of Cooperative Work among Lecturers}

Cooperative work among lecturers is not easy, demanding as it does numerous requirements which are not always fomented by the teaching environment. Nevertheless it is a worthwhile task. Numerous authors have outlined the benefits of cooperative work among teachers (Little, 1996; Hargreaves, 1995):

1. It offers moral support and assurance to group members, increasing the possibility to carry out research tasks and to put innovative ideas into practice.

2. It increases coordination between teachers, encouraging their involvement, to the benefit of the degree course and the centre.

3. It reduces excess work, since responsibilities and pressure are shared.

4. It increases teachers' capacity for reflection and facilitates access to new ideas and creativity.

5. It provides more opportunities to learn and foments continual improvement.

6. It supports social transformation and a change of values.

As we have seen, cooperative work provides many advantages, but the most important one is the moral support and assurance that it provides to group members. Our experience as a teaching group has shown us that working together as a team we feel more confident, since our teaching work is backed up by our fellow team members. According to (Hargreaves, 1995), this support constitutes one of the principles which facilitate perfectionning and improvement of teaching. Through cooperative work the most vulnerable aspects of teaching are shared, thus reducing uncertainty, strengthening personal resolve and overcoming failure and frustration which might otherwise stand in the way of improvement. This personal betterment promotes the professional development of the 
lecturers who practise it. Among the principles which Hargreaves claims can be achieved through cooperative work, two are directly related to the above-mentioned development as professionals: opportunities for learning and the stimulus for continual improvement. Cooperative teamwork increases lecturers' opportunities to learn from one another, as in cooperating they seek solutions to the problems which arise, and in this way they perfect their methodology. Learning and improvement are based on cooperative relationships.

Improving teaching performance implies evolving in thought and behaviour in the most integrated way possible. The person, their knowledge and know-how must all advance. We cannot talk of teacher development without talking of training. The two concepts are closely linked. Professional development occurs when teachers exercise their capacity to reflect on the educational decisions taken and to reason through those decisions bearing in mind the social and political context. According to (Helsby, 2000), the two most important ways in which cooperation foments professional development are the access it provides to new ideas and the increase in lecturers' self-confidence to adopt innovation. Once again it is clear that a lesser degree of uncertainty constitutes a positive element for innovation and professional development.

Johnson states that in cooperative work lecturers seek to satisfy their needs by sharing and cooperative exchange. When they offer and obtain security and psychological support, they are attending their personal needs; if they give and receive pedagogic advice they are satisfying instructional needs; and finally, when they organise the coordination of their students' learning they are attending organisational needs. The latter appear with the convenience of coordinating the students' learning and of achieving greater coherence among classes. This has several consequences, (Johnson, 1999):

1. It multiplies lecturers' efficiency, as they all share the same aims, attitudes and ideas.

2. It allows us to identify what is important and to discard what is not, without incurring in contradictions and incoherent attitudes.

3. It helps to avoid the omission of key aspects or unnecessary repetition.

4. It increases the coherence of the teaching team as they are all acting along the same lines of cooperative work for the benefit of the students.

5. It allows attitudes to be developed which would not be attained by the individual work of isolated lecturers.

One of the basic recommendations for the Implantation of the European Higher Education Space is that innovative educational work should be carried out in the framework of a coordinated teaching team, and not in an individual manner in each subject. Some specific examples in which lecturers will have to coordinate to fulfil these goals are (Montoya, 2008):

1. Analysing as a whole the students' workload and schedule (total number of hours or the effort required both inside and outside the classroom according to the ECTS), in such a way that the total work demanded of the student is suitable and is distributed reasonably each week.

2. Drawing up a chronogram of evaluations and work to be handed in, with optimum distribution from the students' point of view, without overlapping of different subjects. 
3. Revision of the work to be covered in order to avoid overlapping, incoherence or omission (horizontal and vertical coordination).

4. Establishing connections between subjects by means of integrated sub-projects of varying size, so that the contents of different subjects are integrated and sequential continuity is established.

5. Designing the itinerary or the competences which will certify what has been learnt from the cross-curricular competences selected.

6. Supporting the use of common active methodologies such as cooperative learning, case studies, problem/ project-based learning, etc., which allow us to develop the itinerary of competences.

7. Assigning tutors for each student, accompanied by a tutoring schedule and a rational timetable (tutorials, seminars, free mornings or afternoons).

8. Proposal of internal or external activities and shared supplementary material.

9. Carrying out surveys as a means of feedback on the process, group reflection and proposals for improvement.

Teamwork, therefore, increases the coordination between lecturers both horizontally and vertically, involves them more in the structure of the degree course, and leads to improved performance of the students, since it facilitates the allocation of responsibilities among lecturers, risk taking and the adoption of different new teaching strategies. In these circumstances the efficiency of the faculty and the course's capacity to respond to the needs of the current environment are greatly enhanced.

\subsection{Benefits of Cooperative Work for the students: the development of competences}

Cooperative work developed through students' cooperative learning guarantees the acquisition of basic social skills which are important for carrying out work and which also require that students are committed to their own learning process, as experience with our students has taught us (Gil et al., 2007; Gil et al., 2008; Montoya et al., 2008). In summary, it promotes the following:

1. Development of interpersonal skills.

2. Development of high level intellectual skills.

3. Responsibility, flexibility and self-esteem.

4. Work of all: each individual bears part of the responsibility towards his/her colleagues.

5. Generation of support networks for students at risk.

6. Generation of a greater degree of enthusiasm and motivation (in both lecturers and students).

7. Promotion of in-depth as opposed to superficial or memory learning.

This relationship also favours the efficient completion of the task and the personal and social relationships of those involved in the cooperation due to the motivation it provides and the superior reasoning it encourages. The personal relationships between participants also become more positive, that is more committed and team-oriented, and the mental health, self-esteem and social development of all participants improve. These benefits of cooperative activity can be grouped in three large categories: better performance, more 
positive relationships and improved mental health. The better performance is due to the greater level of reasoning and motivation which the group foments. As regards the capacity to reason, constructivism provides students with the chance to mediate and learn from one another. This interaction leads them to socio-cognitive conflict and provides them with the opportunity to help themselves in the zone of close development (Duran Gisbert, 2001). Cooperation also constitutes a social strategy and a chance for personal betterment. Belonging to a group implies forming part of a collective which offers security and friendship, but also the communication established between group members cements a relationship which satisfies their needs, desires, motivations and interests. It also leads to the growth of their personal identity, as they appropriate beliefs, emotions and motivations which are present in the collective. The individual and social development of group members is therefore promoted.

The collective process involved in cooperation also favours the participants' social development by increasing their degree of social maturity and their socialisation resources.

\subsection{Our Teaching Group and the use of the Virtual Platform}

In the field of education, new information and communication technologies are giving rise to a wide variety of tools which greatly facilitate not only the students' learning process, but also the coordination between lecturers.

Our teaching group (COMPING), was created both as a training project and to foment a coordinated and united teaching team with a common approach and aims (Montoya et al., 2007; Montoya et al., 2008). Our way to work and communicate has been via the WebCt platform (Fig. 1). This has allowed us to develop our own knowledge of the abovementioned topics on the one hand, and to practise the coordination of a course as if we were a teaching team on the other. Working in this way has also allowed us to reduce the number of meetings to be attended while at the same time maintaining daily communication with each other.

In this way the course created for the platform fulfils three fundamental tasks:

- First of all, as commented previously, it constitutes a forum and meeting point for all the lecturers in the team.

- $\quad$ Secondly, all updated general information generated by a given group is available to students at any time throughout the course.

- $\quad$ Finally, the university community as a whole can find all the actions developed in the framework of the project and take an active part active in its progress. 

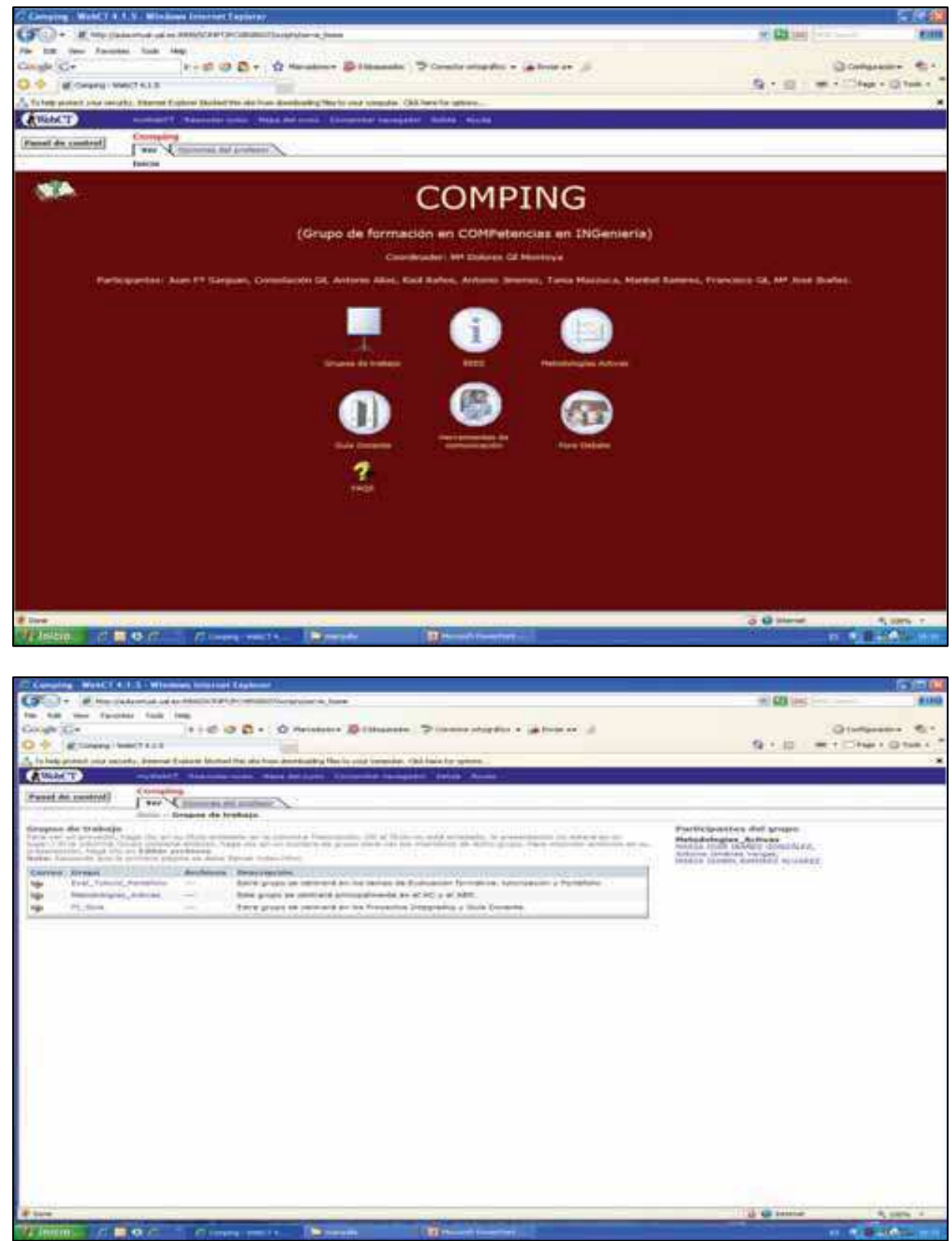

Fig. 1. Example of the course created on the WebCt platform for our teaching group "Comping" (Work on engineering competences) with three cooperative work groups. 


\section{Proposals to promote Cooperative Work among teaching staff}

In our experience, cooperation has many advantages: it provides the chance to carry out difficult tasks thanks to the support of the group; it increases coordination among teaching staff and involves them in the improvement of the degrees and centres/faculties; but most importantly, the members of the group give each other moral support and confidence. Most of the teachers involved feel that they carry out their professional duties with a greater feeling of confidence and with the backing of their colleagues.

Through cooperation, according to (Johnson, 1991), lecturers satisfy personal needs, obtaining security and psychological support; they satisfy teaching needs, as they receive pedagogic advice; and they satisfy organisational needs on coordinating their students' learning. Though all three types of needs are important, the personal ones are particularly so, since our experience as a teaching group has shown us that confidence and psychological support are indispensable for professional innovation and development. Lecturers usually conceptualise this development as personal enrichment, they continually refer to it as one of the most important advantages of cooperative work.

One of the ways cooperation contributes to improving teaching is its capacity to foment innovations in degrees.

If we want practical innovation to be encouraged in our classes, therefore, we should turn to cooperation with other lecturers. As we can see in the following quote, is of the same opinion, basing the capacity to implement reforms on the learning of behaviour, skills and beliefs which are produced through interaction:

"The theory of change which I have been expounding clearly points to the importance of the relationships between colleagues in the same centre. Changing implies learning to do something new, and interaction is the cornerstone of social learning. The new sense, new behaviours, skills, abilities and beliefs depend to a significant degree on whether the teaching staff work in isolation or exchanging ideas, support and positive feelings on their work. The quality of work relations among staff is linked closely to its implementation." (Fullan, 1999).

If we wish to promote cooperative work we will have to implement measures which help to encourage this type of activity. These measures should be established from all areas or institutions which have something to say on the matter: educational authorities, universities, centres and faculties and their management teams, departments, teaching staff and other groups such as teacher training units.

Going back to the first point, the existence of common goals, brings us to the final aim of this chapter: how to develop cooperative work in the centre/faculty and in the classroom.

1. To develop initiatives of cooperative work and teamwork it is necessary to promote interest in carrying out common projects.

2. Teaching groups must have the autonomy to decide the contents of their teaching activity and the time needed to carry it out. Only in this way can true cooperation be achieved.

3. It would be convenient to analyse the type of cooperative work adopted by a group, to evaluate and take advantage of the possibilities it offers, and to continue progressing toward a greater degree of interaction.

4. To improve the teaching-learning process and to enhance teaching professionality, teaching staff should work in teams. This practice provides numerous advantages such as 
offering moral support for innovation and reform, improving the capacity for analysis, and supporting the change in values.

5. Cooperative work improves self-esteem and gives rise to the establishment of shared norms, bonds of affection and social relationships. By recognising others as people we can relate to and work with, we participate in an experience of personal development and social solidarity.

6. Cooperative work should be promoted to improve the training of lecturers and their professional development.

7. To facilitate cooperative work we should try to ensure that the group members possess certain characteristics such as compatible educational beliefs, willingness to debate and democratic attitudes. We should also try to minimise the effects of competitiveness and the lack of cooperative tradition in education and the existence of universities and centres/faculties whose organisational structures make cooperation difficult.

8. To combat the individualism which usually characterises teaching and prevents access to new ideas, we should promote, within a cooperative framework, that individuality which encourages the teachers' initiative and creative strength.

9. We should ensure that the cooperative work is authentic, not simply a process of artificial collaboration masquerading as joint work but not providing any of its benefits.

10. Centres/faculties should do their best to avoid situations of collaboration in isolated groups, such as departments or areas, which prevent the development of the centre or faculty as a whole.

11. When evaluating the performance of teaching staff, we should take into account the merits achieved through cooperative activities and teaching coordination.

12. New organisational structures should be created which include several departments or which are transversal to several of them. This would alleviate the balkanization effect which the current structures produce.

13. We should design and promote organisational structures which complement the different areas and departments in centres and faculties. These structures would group the teaching staff according to alternative criteria which each centre should establish (projects to be developed, priorities, activities, etc.). In this way collaboration would be encouraged by working within structures which the centre would establish according to its own goals.

14. We should create mechanisms by which the teaching staff can cooperate in voluntary groups which deal with topics of personal and common interest.

15. The times at which the teaching staff are not directly occupied with students should coincide.

16. Areas and departments should be managed truly democratically in order to avoid them becoming politicised groups in which the struggle for power and status leads to an organisation of work segmented into balkanized groups.

17. The management team should organise the distribution of teaching work in such a way as to make cooperation necessary.

18. Centres and faculties should assess the evolution of their collaborative processes, bearing in mind the processes themselves rather than the ends achieved.

19. We should foment and reinforce the evolution of teaching organisations that are structured horizontally and vertically, in which cooperative work is the basis for achieving common aims. 
20. The initial training of teaching staff should be substantially modified, including in the curricula contents which encourage reflection on cooperative activities and their advantages, using methodologies aimed at practising cooperation in all subjects, while also promoting collaboration among the teaching staff in charge of training.

21. Permanent training of teaching staff should pay special attention to cooperation, on the one hand as an element of the working methodology in the classroom, and on the other as a topic for study and consideration in the methodology of the centre.

22. Permanent training activities should also be modified substantially, preferably basing methodology on cooperation among lecturers, given the great potential of this activity for professional development.

23. Both initial and permanent training should encourage skills of interpersonal exchange and awareness of group functions.

24. All parties involved in the educational process should ensure that suitable conditions are created and maintained for cooperation among lecturers to be both necessary and possible, thus contributing towards the development of a culture of cooperation.

The development of collaborative cultures in educational centres carries multiple pedagogic, social and political implications. As authors such as (Tonucci, 1981) or (Freire, 1984) have long expounded, collaborating and cooperating with colleagues in teaching tasks implies committing oneself to a society based on different values; now we also know that cooperation brings us many benefits, such as stimulating our professional evolution and creating emotional bonds which enrich us and allow us to recognise ourselves by recognising our colleagues as people with whom we wish to share. The intuition which guided us in our first years of teaching has with time become a conviction: more than ever we consider it necessary to build a society in which cooperation is considered positively, while at the same time rejecting competitiveness and the hierarchy that goes with it. In short, we wish to foment a society in which a culture of cooperation can be developed; one which recognises the priority of ethics and justice over the market, and which is based on collective values of solidarity.

\section{Conclusions, Cooperative Work: The Great Challenge}

This cooperative culture is not characterised by the number of meetings called or by how long they last, but rather by the depth of the relationships created and the way in which cooperation extends to all areas, enabling it to improve continually. Moreover, the importance of cooperative work goes much further, as it implies committing to an educational system and a society based on values which are opposed to individualism and competition. This is, in fact, the true challenge facing cooperative work.

The results obtained with cooperative work surpass the individual capabilities of the group members, as the group is the sum of its parts. Indeed, cooperative work has allowed us to carry out a whole process of reflection, training and innovation in our own teaching practice. In short, the numerous positive consequences that cooperative work offers both students and lecturers are: it reduces uncertainty, facilitates access to new ideas, improves efficiency and efficacy, reduces overload of work, increases the capacity for reflection, makes needs of different types common elements, achieves better performance, establishes more positive personal relationships, enhances mental health, stimulates creativity, allows 
us to understand better how others think, defends professional interests and demands, adapts the curriculum to the context and to the students' needs, and above all creates the bases for new theoretical constructions, increases opportunities to learn, to improve continuously and to advance in one's professional career. Cooperation, moreover, constitutes the basis for any innovation, whether among lecturers or students. Sharing common aims in educational programming, taking them into the classroom and assessing them as a team allows lecturers to learn and improve continually. Teacher training should foment the skills of teamwork.

Another of the facts which underline the current need for teamwork among lecturers is the importance that cooperative work takes on in teaching teams. The compartmentalization which characterizes education today, and the resulting desprofessionalization in the competence of relating knowledge, requires a reprofessionalization in the new competence of cooperating in the framework of a teaching team. Cooperative work, therefore, is more necessary today than ever before. However, the importance of cooperation goes further still, as it implies a move towards a society based on different values.

Generally speaking, those lecturers who work in a team with their colleagues tend to practice this activity in the classroom with their students, because cooperative work is not a technical process, but rather an attitude which suffuses all aspects of the educational centre and conforms the culture of collaboration which spreads to all moments and situations, providing the assurance that we can abandon teaching based on control. This culture is not characterized by the meetings which are held, but rather by the relationships maintained, with a predominant atmosphere of help, confidence and mutual sincerity. What remains uppermost in our minds from our experiences of cooperative work is not the results obtained, but rather the very process of joint work.

Cooperation and teamwork are necessary and can make a decisive contribution to improving the educational system. Despite the difficulties this type of work entails, it constitutes one of the most urgent needs of current education. It also supposes a real challenge: that of achieving a new education for a better society.

Cooperative work among lecturers implies a definitive change in values, opting for a different, more equalitarian society in which we all seek and learn: a move from "I think " to "we believe".

\section{References}

Angulo Rasco J. F. et al. (2000). Pedagogías del siglo XX. Barcelona. Cisspraxis. Spain.

Arnaus, R. (1999). "La formación del profesorado: Un encuentro comprometido con la complejidad educativa" In Pérez Gómez, A.; Barquín Ruiz, J., Angulo Rasco, J. F (Eds.) Desarrollo profesional del docente política, investigación y práctica. Madrid. Akal. 1999. Spain.

Aronson, E., \& Patnoe, S. (1997). The jigsaw classroom: Building cooperation in the classroom (2nd ed.). New York: Addison Wesley Longman.

Book, C. L. (1996). Professional development schools. In SIKULA, J. (Ed.). Handbook of research on teacher education, pp. 194-212. USA. McMillan Library. 1996.

Clemente Linuesa, M. (1999). ¿Es posible una cultura de colaboración entre el profesorado?. Revista de Educación, no. 320, , pp. 205-221. 1999.

Day, C. (1999). Developing teachers. The challenges of lifelong learning. London and Philadelphia. Falmer Press. 1999. 
Duran Gisbert, D. (2001). Cooperar para triunfar. Cuadernos de Pedagogía no. 298, enero, pp. 73-75. Barcelona. Cisspraxis. Spain.

EHES, (2005). The European Higher Education Area- Achieving the Goals. Communiqué of the Conference of Ministers responsible for Higher Education in Bergen on 19 May 2005 (http:/ / www.blogna-bergen2005.no).

Fernández, A. (2006). Nuevas Metodologías docentes. Apuntes del taller organizado por la Unidad de Formación del profesorado de la Universidad de Almería. Spain

Freire, P. (1984). Pedagogía del oprimido. Madrid. Siglo XXI.

Fullan, M. (2001). Leading in a culture of change. San Francisco.Jossey-Bass.

Gil, C.; Montoya, M. G.; Alías, A.; Baños, R. (2007). Comparative Study Between Individual and Group Activities. International Technology, Education and Development Conference. ISBN:978.84-611-4516-4.Valencia, Marzo. 2007.Spain

Gil, C.; Montoya, F. G.; Baños, R.; Alías, A.; Montoya, M. G. (2008). Competencies Development in Engineering via Active Methodologies. International Technology, Education and Development Conference, ISBN: 978-84-612-0192-1.Valencia, Marzo. 2008. Spain.

Gimeno Sacristán, J. (1988). El currículum: una reflexión sobre la práctica. Morata. 1988

Gitlin, A. (1987). Common school structures and teacher behaviour. In SMYTH, J. (Ed.). Educating teachers. Changing the nature of pedagogical knowledge pp. 107-119. Lewes. The Falmer Press. 1987.

Habermas, J. (1997). Teoría de la acción comunicativa. Complementos y estudios previos. Madrid. Cátedra. Spain

Hargreaves, A. (1995). La modificación de las culturas de trabajo de la enseñanza. Kikirikí Cooperación Educativa, n. 35, diciembre 94-febrero 95,pp. 49-61. 1995.

Helsby, G. (2000). Multiple truths and contested realities. The changing faces of teacher professionalism in England. In DAY, C.; FERNÁNDEZ, A., HAUGE, T. E. y MOLLER, $J$. (Eds.) The life and work of teachers. International perspectives in changing times, pp. 93-108. Nueva York. Falmer Press.

Johnson D. W.; Johnson R. T. \& Smith K. A (1991). Cooperative Learning: Increasing Collage Faculty Instructional Productivity, Vol. 20, No. 4.

Johnson, D. W.; Johnson, R. T. \& Holubec, E. J. (1999). El aprendizaje cooperativo en el aula. Barcelona. Paidós.

Johnson D. W.; Johnson R. T. \& Smith K. A. (2006). Active Learning: Cooperation in the College Classroom. Edina, MN., Interaction Book Company. Third Edition.

Little, J. W. (1996). Teachers as Colleagues. In LIEBERMAN, A. (Ed.): Schools as collaborative cultures: creating the future now, pp.165 -193. London. Falmer Press.

López, A. (2007). El trabajo en equipo del profesorado. Editorial GRAÓ. 2007.

Martínez Bonafé, J. (1998). Trabajar en la escuela. Madrid. Miño y Dávila. Spain

Montoya, M. G.; Gil, C.; Alías, A. \& Montoya, F. G. (2007). The Importance of Teaching Teams as a Formative and Innovation Strategy. International Technology, Education and Development Conference. ISBN:978.84-611-4516-4. INTED. Valencia, Marzo 2007. Spain.

Montoya, M. G.; Gil, C.; Baños, R.; Montoya, F. G. \& Alías, A. (2008). Cooperative work in the faculty and in the classroom: a key to coordination of the teaching staff and development of students' competences. International Technology, Education and 
Development Conference. 1. ISBN: 978-84-612-0192-1. INTED. Valencia, Marzo 2008. Spain.

Rosenholtz, S. J. (1989). Teacher's workplace. The social organization of schools. Columbia. Teachers College Press. 1989

Tonucci, F. (1981). Viaje alrededor de "El Mundo". Diario de Mario Lodi y sus amigos. Laia. Barcelona. Spain.

Tunning, (2002). Tuning Educational Strucrtures in Europe. Informe Final Proyecto Piloto Fase I. 2002 (http:/ / www.relint.deusto.es/TUNINGProject/index.htm). 


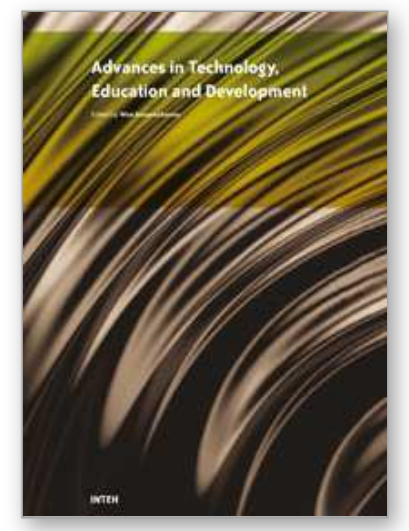

\section{Advances in Technology, Education and Development \\ Edited by Wim Kouwenhoven}

ISBN 978-953-307-011-7

Hard cover, 474 pages

Publisher InTech

Published online 01, October, 2009

Published in print edition October, 2009

From 3rd to 5th March 2008 the International Association of Technology, Education and Development organised its International Technology, Education and Development Conference in Valencia, Spain. Over a hundred papers were presented by participants from a great variety of countries. Summarising, this book provides a kaleidoscopic view of work that is done, all over the world in (higher) education, characterised by the key words 'Education" and 'Development'. I wish the reader an enlightening experience.

\section{How to reference}

In order to correctly reference this scholarly work, feel free to copy and paste the following:

M. G. Montoya, R. Herrada, C. Gil, F. G. Montoya and A. Alias (2009). The Importance of Cooperative Work in the Faculty and in the Classroom, Advances in Technology, Education and Development, Wim Kouwenhoven (Ed.), ISBN: 978-953-307-011-7, InTech, Available from: http://www.intechopen.com/books/advances-intechnology-education-and-development/the-importance-of-cooperative-work-in-the-faculty-and-in-theclassroom

\section{INTECH}

open science | open minds

\author{
InTech Europe \\ University Campus STeP Ri \\ Slavka Krautzeka 83/A \\ 51000 Rijeka, Croatia \\ Phone: +385 (51) 770447 \\ Fax: +385 (51) 686166 \\ www.intechopen.com
}

\author{
InTech China \\ Unit 405, Office Block, Hotel Equatorial Shanghai \\ No.65, Yan An Road (West), Shanghai, 200040, China \\ 中国上海市延安西路65号上海国际贵都大饭店办公楼 405 单元 \\ Phone: +86-21-62489820 \\ Fax: $+86-21-62489821$
}


(C) 2009 The Author(s). Licensee IntechOpen. This chapter is distributed under the terms of the Creative Commons Attribution-NonCommercial-ShareAlike-3.0 License, which permits use, distribution and reproduction for non-commercial purposes, provided the original is properly cited and derivative works building on this content are distributed under the same license. 